\title{
Molecular epidemiology of Plasmodium falciparum by multiplexed amplicon deep sequencing in Senegal
}

\author{
Tolla Ndiaye ${ }^{1 *}$, Mouhamad Sy ${ }^{1}$, Amy Gaye ${ }^{1}$, Katherine J. Siddle², Daniel J. Park², Amy K. Bei ${ }^{3}$, Awa B. Deme ${ }^{1}$, \\ Aminata Mbaye ${ }^{1}$, Baba Dieye ${ }^{1}$, Yaye Die Ndiaye ${ }^{1}$, Ibrahima Mbaye Ndiaye ${ }^{1}$, Mamadou Alpha Diallo', \\ Khadim Diongue ${ }^{1}$, Sarah K. Volkman ${ }^{2,4}$, Aida Sadikh Badiane ${ }^{1}$ and Daouda Ndiaye $e^{1,4}$
}

\begin{abstract}
Background: Molecular epidemiology can provide important information regarding the genetic diversity and transmission of Plasmodium falciparum, which can assist in designing and monitoring elimination efforts. However, malaria molecular epidemiology including understanding the genetic diversity of the parasite and performing molecular surveillance of transmission has been poorly documented in Senegal. Next Generation Sequencing (NGS) offers a practical, fast and high-throughput approach to understand malaria population genetics. This study aims to unravel the population structure of P. falciparum and to estimate the allelic diversity, multiplicity of infection (MOI), and evolutionary patterns of the malaria parasite using the NGS platform.

Methods: Multiplex amplicon deep sequencing of merozoite surface protein 1 (PFMSP1) and merozoite surface protein 2 (PfMSP2) in fifty-three P. falciparum isolates from two epidemiologically different areas in the South and North of Senegal, was carried out.

Results: A total of 76 Pfmsp 1 and 116 Pfmsp2 clones were identified and 135 different alleles were found, 56 and 79 belonged to the pfmsp 1 and pfmsp2 genes, respectively. K1 and IC3D7 allelic families were most predominant in both sites. The local haplotype diversity $(\mathrm{Hd})$ and nucleotide diversity $(\pi)$ were higher in the South than in the North for

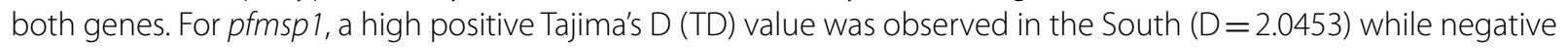
TD value was recorded in the North ( $D=-1.46045)$ and F-Statistic (Fst) was 0.19505. For pfmsp2, non-directional selection was found with a highly positive TD test in both areas and Fst was 0.02111 . The mean MOI for both genes was 3.07 and 1.76 for the South and the North, respectively, with a statistically significant difference between areas $(p=0.001)$.

Conclusion: This study revealed a high genetic diversity of pfmsp 1 and pfmsp 2 genes and low genetic differentiation in P. falciparum population in Senegal. The MOI means were significantly different between the Southern and Northern areas. Findings also showed that multiplexed amplicon deep sequencing is a useful technique to investigate genetic diversity and molecular epidemiology of P. falciparum infections.
\end{abstract}

Keywords: Molecular epidemiology, Plasmodium falciparum, Pfmsp1, Pfmsp2, Multiplexed amplicon deep sequencing, $\mathrm{MOI}$

*Correspondence: ndiayetola@gmail.com

${ }^{1}$ Laboratoire de Parasitologie-Mycologie, Université Cheikh Anta Diop de Dakar (UCAD), Hôpital Aristide Le Dantec, Dakar, Senegal

Full list of author information is available at the end of the article

\section{Background}

Plasmodium falciparum is the deadliest species of human malaria parasites $(99.7 \%)$ and the most prevalent in Africa, responsible for $92 \%$ of malaria cases and $93 \%$ of

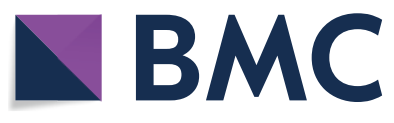

(c) The Author(s) 2020. This article is licensed under a Creative Commons Attribution 4.0 International License, which permits use, sharing, adaptation, distribution and reproduction in any medium or format, as long as you give appropriate credit to the original author(s) and the source, provide a link to the Creative Commons licence, and indicate if changes were made. The images or other third party material in this article are included in the article's Creative Commons licence, unless indicated otherwise in a credit line to the material. If material is not included in the article's Creative Commons licence and your intended use is not permitted by statutory regulation or exceeds the permitted use, you will need to obtain permission directly from the copyright holder. To view a copy of this licence, visit http://creativeco mmons.org/licenses/by/4.0/. The Creative Commons Public Domain Dedication waiver (http://creativecommons.org/publicdomain/ zero/1.0/) applies to the data made available in this article, unless otherwise stated in a credit line to the data. 
death caused by malaria [1]. A better understanding of malaria epidemiology could be helpful for disease control and prevention. The extent of genetic diversity and multiplicity of infection (MOI) are essential to understand malaria epidemiological patterns, providing insight into the dynamics of malaria transmission, human exposure to mosquito bites, acquisition of malaria immunity [2-5] and assessing of malaria control interventions [6-8].

Plasmodium falciparum merozoite surface protein 1 (PfMSP1) and merozoite surface protein 2 (PfMSP2) are polymorphic antigens which have been extensively studied in malaria molecular epidemiology [9-11]. Polymerase chain reaction (PCR)-based genotyping of the polymorphic regions of the corresponding genes (block 2 of Pfmsp 1 and block 3 of Pfmsp2) can be used to assess the allelic diversity and to determine MOI [12]. Therefore, many previous studies have used these two markers in order to evaluate genetic diversity, population structure and MOI [13-16]. However, these PCR-based methods may underestimate the extent of allelic diversity in co-infected hosts due to the use of size-polymorphisms to infer alleles; a particular problem when using short fragment amplification [17-19]. Microsatellite typing is an alternative tool to assess genetic diversity but might fail to detect many minor clones as it requires a cut-off of $33 \%$ of the predominant peak for a minimal peak height [20-22]. Similarly, high resolution melting (HRM) has been used for genotyping of single nucleotide polymorphisms (SNP), but shows limitations in the detection of indels [23]. Advances in next generation sequencing (NGS) technologies and bioinformatic analysis has enabled the accurate detection of clones and even minor clones, overcoming the limitations of these other methods [24]. These techniques provide a more accurate estimation of MOI compared to the standard PCR-based methods $[25,26]$ and accurate assessment of genetic diversity in $P$. falciparum populations [27]. For example, amplicon deep sequencing of Pfmsp1 from 222 samples collected in Ethiopia revealed 307 haplotypes out of which 99 were predominant haplotypes (the clone had the highest frequency within infection). In addition, a mean MOI of 2.68 was found by this study [24].

In Senegal, most of the studies about $P$. falciparum genetic diversity and malaria molecular epidemiology $[7,8,28-30]$ have been carried out in the Thies region, a low malaria endemicity area. Thus, limited information on malaria molecular epidemiology are available for other areas of the country and further detailed studies are needed to understand the genetic diversity and population structure country-wide. Here, multiplexed amplicon deep sequencing of Pfmsp 1 and $P f m s p 2$ genes in $P$. falciparum isolates sampled from a malaria hyperendemic area in the South (Kedougou region) and a pre-elimination areas in the North (Podor and Matam) was performed. This data was used to understand the population structure, to estimate allelic diversities and MOI, and to understand the population dynamics, gene flow and evolutionary pattern of the malaria parasite $P$. falciparum in Senegal.

\section{Methods}

\section{Study sites, sample collection}

This study was conducted in Kédougou region, (KG, Southern Senegal) and Podor and Matam (PM, Northern Senegal). Kédougou (685 km from the capital, Dakar) (Fig. 1) is hyper-endemic for malaria with an incidence higher than fifteen malaria cases per 1000 habitants. In this area, malaria transmission is seasonal from July to December with a high entomological inoculation rate (EIR) ranging from 20 to 100 infectious bites/person/ year [31]. In contrast, Northern Senegal (Podor and Matam, Fig. 1) is a malaria pre-elimination area with an incidence of less than five cases per 1,000 habitants and an EIR equal to 1.3 infectious bites/person/ year [31].

Samples were collected from patients with malaria symptoms attending the National Malaria Control Programme (NMCP) sentinel site health facilities during malaria transmission season between September and December 2016 (Fig. 1). In the South, venous blood samples were collected on filter paper from patients fulfilling the following inclusion criteria: having fever (axillary temperature $\geq 37.5^{\circ} \mathrm{C}$ ) or history of fever in the previous $48 \mathrm{~h}$, age ranging from 6 months to 75 years and suffering from uncomplicated $P$. falciparum malaria with parasite density $\geq 1000$ asexual forms per microlitre. Patients who presented signs or symptoms of severe malaria as defined by the World Health Organization (WHO) [32] and pregnant women were not included in the study. In the North, P. falciparum positive rapid diagnostic tests (RDTs) were collected in health facilities (NMCP sentinel sites) in Matam and Podor.

\section{Amplification and sequence analysis of Pfmsp1 and Pfmsp2} The experimental workflow from amplicon preparation to data analysis are detailed in Fig. 2.

\section{Multiplex PCR amplification of Pfmsp1 and Pfmsp2 genes}

Parasite genomic deoxyribonucleic acid (DNA), from filter paper and RDTs was extracted using QIAamp DNA Mini kit (Qiagen, QIAGEN, USA) according to the manufacturer's instructions. Plasmodium falciparum molecular identification was performed using the photo-induced electron transfer (PET)-PCR assay [33] on a Roche LightCycler 96 instrument (Roche Molecular Systems, Inc). Each experimental run included both a negative (no template) and a positive (3D7 P. falciparum 


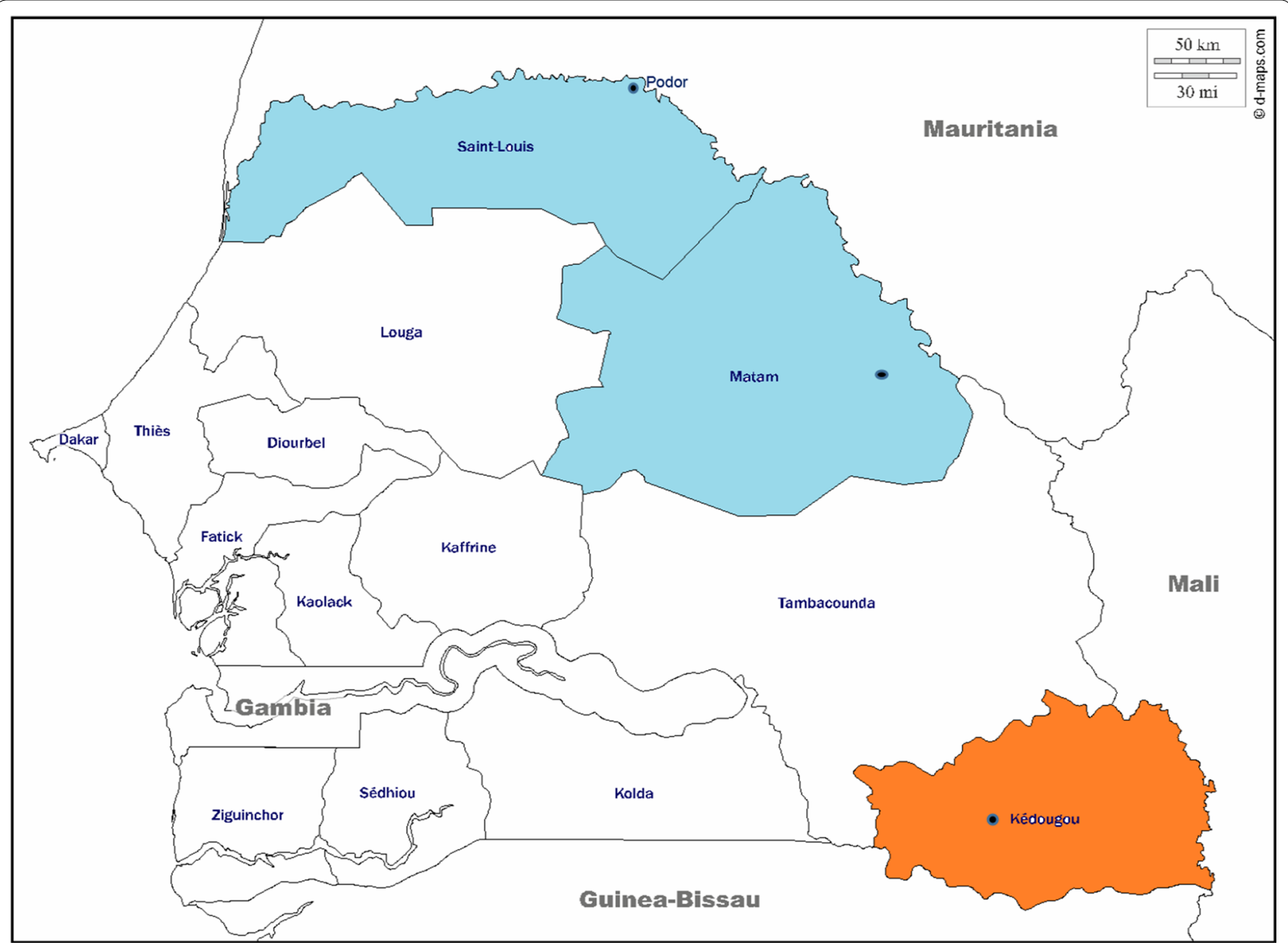

Fig. 1 Map of Senegal showing the two malaria studies areas, Kedougou in orange (Southern Senegal) and Podor and Matam in blue (Northern Senegal). This map was generated using online website (https://www.d-maps.com)

strain) control. Samples with a cycle threshold (CT) of 40 or less were scored as positive [33,34]. The two Pfmsp1 and $P f m s p 2$ polymorphic genes were amplified by multiplex PCR. All PCR reactions were conducted in a $20 \mu \mathrm{l}$ reaction mixture containing $2 \mu \mathrm{l}$ of template DNA, $4 \mu \mathrm{l}$ Phusion high-fidelity (HF) PCR master mix, $0.2 \mu \mathrm{l} \mathrm{HF}$ Phusion Taq Polymerase, $250 \mu \mathrm{M}$ deoxyribonucleotide triphosphate (dNTPs), $0.5 \mu \mathrm{M}$ of each forward and reverse primer of each gene. Cycling conditions were as follows: initial denaturation at $94{ }^{\circ} \mathrm{C}$ for $5 \mathrm{~min}$, followed by 40 cycles of denaturation at $94{ }^{\circ} \mathrm{C}$ for $30 \mathrm{~s}$, annealing at $58{ }^{\circ} \mathrm{C}$ for $1 \mathrm{~min}$ and extension at $68^{\circ} \mathrm{C}$ for $1 \mathrm{~min}$ $40 \mathrm{~s}$; a final extension was done at $68{ }^{\circ} \mathrm{C}$ for $5 \mathrm{~min}[23$, 35]. The PCR products were revealed by electrophoresis on $2 \%$ agarose gels stained with ethidium bromide and visualized under ultraviolet (UV) trans-illumination (VersaDoc ${ }^{\circledR}$, BIORAD, Hercules, USA). The size of PCR fragments was estimated using a $100 \mathrm{bp}$ molecular weight ladder (Fig. 2a). The length of PCR product varied from $800-1000 \mathrm{bp}$ and from 600 to $800 \mathrm{bp}$ for Pfmsp 1 and Pfmsp2, respectively.

\section{Multiplex amplicon deep sequencing of Pfmsp 1 and Pfmsp2}

Amplicons from each sample were purified using a 0.6X DNA SPRI (Agencourt AMPure XP beads Beckman Coulter ${ }^{\circledR}$, CA, USA). Samples were normalized to $0.25 \mathrm{ng} / \mu \mathrm{l}$ concentration using the Qubit ${ }^{\circledR} 3.0$ Fluorometer and Invitrogen ${ }^{\text {TM }}$ Qubit ${ }^{\circledR}$ Quantitation Kit (Life Technologies, Carlsbad, California). The Nextera XT DNA Library Preparation kit (Illumina, USA) was used for library preparation of $1 \mathrm{ng}$ of purified PCR product from each sample [36]. Sequencing libraries were cleaned using a $0.6 \mathrm{X}$ DNA SPRI and quantified by qPCR using the KAPA Library Quantification kit (KapaBiosystems, MA, USA) on a Roche LightCycler 96 instrument. The concentration of sequencing libraries was normalized and all samples were pooled. The concentration and mean fragment length of the pool were determined using 


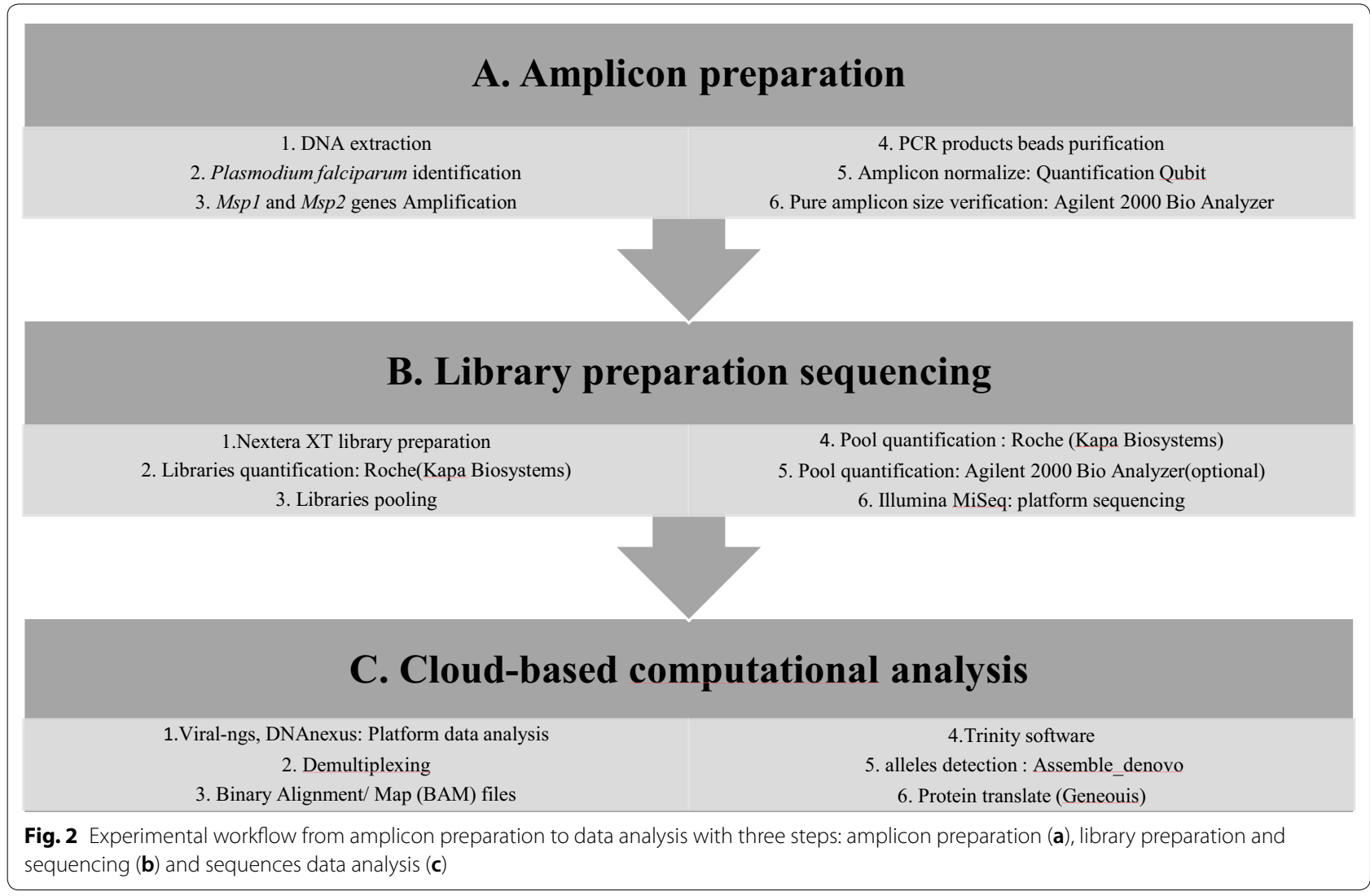

the Agilent High Sensitivity DNA Kit (2100 Expert Software) and the concentration was confirmed by KAPA qPCR. The pool of all samples was sequenced on one run of an Illumina Miseq sequencer with a Miseq v2 reagent Kit (VEROGEN, North America) and 100nt paired end sequencing (Fig. 2b).

\section{Data analysis}

Sequencing data was analysed using viral-ngs, version 1.19.2 pipeline implemented on the DNAnexus cloudbased platform [37]. Briefly, raw reads were demultiplexed to individual sample libraries and reads mapping to the human genome or to other known technical contaminants (e.g., sequencing adapters) were removed. After filtering the reads, they were assembled based on Pfmsp1 or Pfmsp2 gene mapping using the Trinity software [38]. For every sample, the number of clones of each gene were determined from the number of contigs generated by Trinity software. Following de-novo assembly, clones were filtered considering an average of k-mer coverage of 2 with length of at least $200 \mathrm{bp}\left[2^{*}(\mathrm{k}-1)\right.$, $k=101]$. The average read coverage of the individual contig was $1000 \times$, the percentage of the average read coverage of individual contig was $1 \%$ of the average read coverage of overall contigs and allele frequencies $>1 \%$.
The clones found were classified into allelic families according to the polymorphism of block 2 of Pfmsp 1 , and block 3 of $P f m s p 2$ using the Geneious software (Fig. 2c). For Pfmsp1, K1-like were characterized by amino acid tripeptide repeat units SAQ, SGT, SGA, SGP, MAD20like by SVA, SGG, SKG, SVT and RO33-like by nonsynonymous amino acid change. For Pfmsp2, IC3D7-like presented GA or SG amino acid dipeptides repeat units and a poly-threonine repeat while FC27-like were characterized by 32 amino acid, ADTIASGSQSSTNSASTSTTNNGESQTTTPTA or its variants and 12 amino acid: ESISPSPPITTT.

For genetic diversity and population structure analysis, DNA sequences were first aligned using BioEdit Sequence Alignment Editor V.7.0.5.3 [39]. DnaSP v. 6.0 software was used to estimate haplotype diversity $(\mathrm{Hd})$, nucleotide diversity $(\pi)$ and Tajima's D (TD) [40, 41]. Genetic differentiation between populations, Wright's F-statistic (Fst), was estimated using Arlequin software version 3.5 [42]. The Geneious software was used to create the neighbour-joining tree in order to identify the number of parasite clusters and parental links between strains.

The MOI mean was calculated by dividing the total number of alleles detected by the total number of 
samples for each gene [43]. The online Biostatgv Student's test (https://biostatgv.sentiweb.fr/?module=tests /student) was used to compare MOI between localities. For all tests, comparisons were considered statistically significant when P-values $<0.05$.

\section{Results}

Fifty-three (53) samples (28 from the South and 25 from the North) were successfully amplified and sequenced for the two polymorphic markers Pfmsp1 and Pfmsp2. All Fastq sequencing data were submitted to the SRA/NCBI database with the following accession numbers: from SRX8632497 to SRX8632549 (https://www.ncbi.nlm.nih. gov/sra/PRJNA642844).

Allelic polymorphisms and population structure of Pfmsp 1 Fifty-one Pfmsp1 gene were successfully assembled from 53 P. falciparum isolates. A total of 76 clones were found of which 47 and 29 in the South and the North, respectively (Additional file 1). Of the detected Pfmsp1 clones, 56 different alleles were identified with 33 in the South area and 23 in the North area. In the South, the 33 alleles found were classified into 3 different allele types: 18 of K1-like, 8 of MAD20-like, and 7 of RO33-like (Table 1). In the K1-like, each allele had different numbers and arrangements of amino acid tripeptide repeat unit SGASAQSGT, SGT or SGPSGT. The MAD20-like were varied by the number of SGGSVA amino acid tripeptide motif. Meanwhile RO33-like was less polymorphic, with only limited numbers of amino acid substitutions. The neighbor-joining tree of different allele types showed two parasite clusters (Fig. 3a). Plasmodium falciparum population presented high level of genetic diversity with high haplotype diversity $(\mathrm{Hd})$ of 0.93 and a nucleotide diversity $(\pi)$ of 0.28306 . The TD test was performed in each

Table 1 number of alleles per allelic family of Pfmsp1 and Pfmsp2 in the South (Kedougou) and the North (Podor and Matam)

\begin{tabular}{llc}
\hline Localities & Kedougou & North area \\
\hline Gene/allelic families & $N$ & \\
Msp1 & 18 & 8 \\
K1-like & 8 & 6 \\
MAD20-like & 7 & 9 \\
RO33-like & 33 & 23 \\
Total alleles & & \\
Msp2 & 35 & 19 \\
IC/3D7-like & 18 & 7 \\
FC27-like & 53 & 26 \\
Total alleles &
\end{tabular}

$N$ number of alleles area in order to identify any deviation from the neutral evolution of parasites and a highly positive TD value was observed in the South $(\mathrm{D}=2.0453)$ with a statistically significantly different $(\mathrm{p}<0.05)$ (Table 2$)$.

In the North, the 23 alleles found were classified into: 8 of K1-like, 6 of MAD20-like and 9 of RO33-like (Table 1). The K1-like were different based on the number of amino acid tripeptide repetition SGASAQSGT or SGPSGT. The MAD20-like varied with SGGSVA repeat unit and RO33like had relatively well conserved sequences. The neighbour-joining tree of different allele types revealed two parasites clusters (Fig. 3b). Parasite population exhibited less genetic variation with $\pi=0.09457$ and $\mathrm{Hd}=0.76$ and a negative TD value was recorded $(D=-1.46045)$, which was not statistically significant (Table 2). A significant genetic differentiation between the South and the North $P$. falciparum populations was observed with Fst $=0.19505(p<0.05)$ (Table 2$)$.

\section{Allelic polymorphisms and population structure of Pfmsp2}

All 53 Pfmsp 2 gene of $P$. falciparum isolates were successfully assembled. A total of 116 clones were found, 76 in the South and 40 in the North (Additional file 2). Among these clones 79 different alleles were identified of which 53 and 26 in the South and the North, respectively.

In the South, among the 53 different alleles detected, 35 belonged to the IC3D7-like while the other 18 were classified into the FC27-like (Table 1). IC3D7-like showed different dimorphic structures based on GA or SG amino acid dipeptides repeat units and polythreonine repeats. Meanwhile, FC27-like varied with (ADTIASGSQSSTNSASTSTTNNGESQTTTPTA) or its variant amino acid succession. The neighbour-joining tree of parasites showed four clusters (Fig. 4a).

In the North, of the detected 26 different alleles, 19 were classified into IC3D7-like and 7 belonged to FC27like (Table 1). IC3D7-like varied with GA or SG amino acid dipeptides repeat units and poly-threonine repeat. FC27-like were different based on the amino acid succession (ADTIASGSQSSTNSASTSTTNNGESQTTTPTA) and the typical non-synonymous substitution of 6 amino acids (SSGNAP) was found at the C-terminal region of 5 of the 7 FC27-like identified. The neighbour-joining tree of different alleles revealed three clusters (Fig. 4b).

The observed genetic diversity was similarly elevated in both regions $(\mathrm{Hd}=0.82$ in the South and $\mathrm{Hd}=0.843$ in the North), and nucleotide diversity was also very similar ( $\pi=0.48339$ in the South and $\pi=0.42473$ in the North). Non-directional selection was found with a highly positive TD test in the two areas, $D=5.21073$ in the South and $\mathrm{D}=3.46684$ in the North with statistically different $(p<0.05)$. The Fst between the two localities showed an almost panmictic population $(\mathrm{Fst}=0.02111)($ Table 2$)$. 


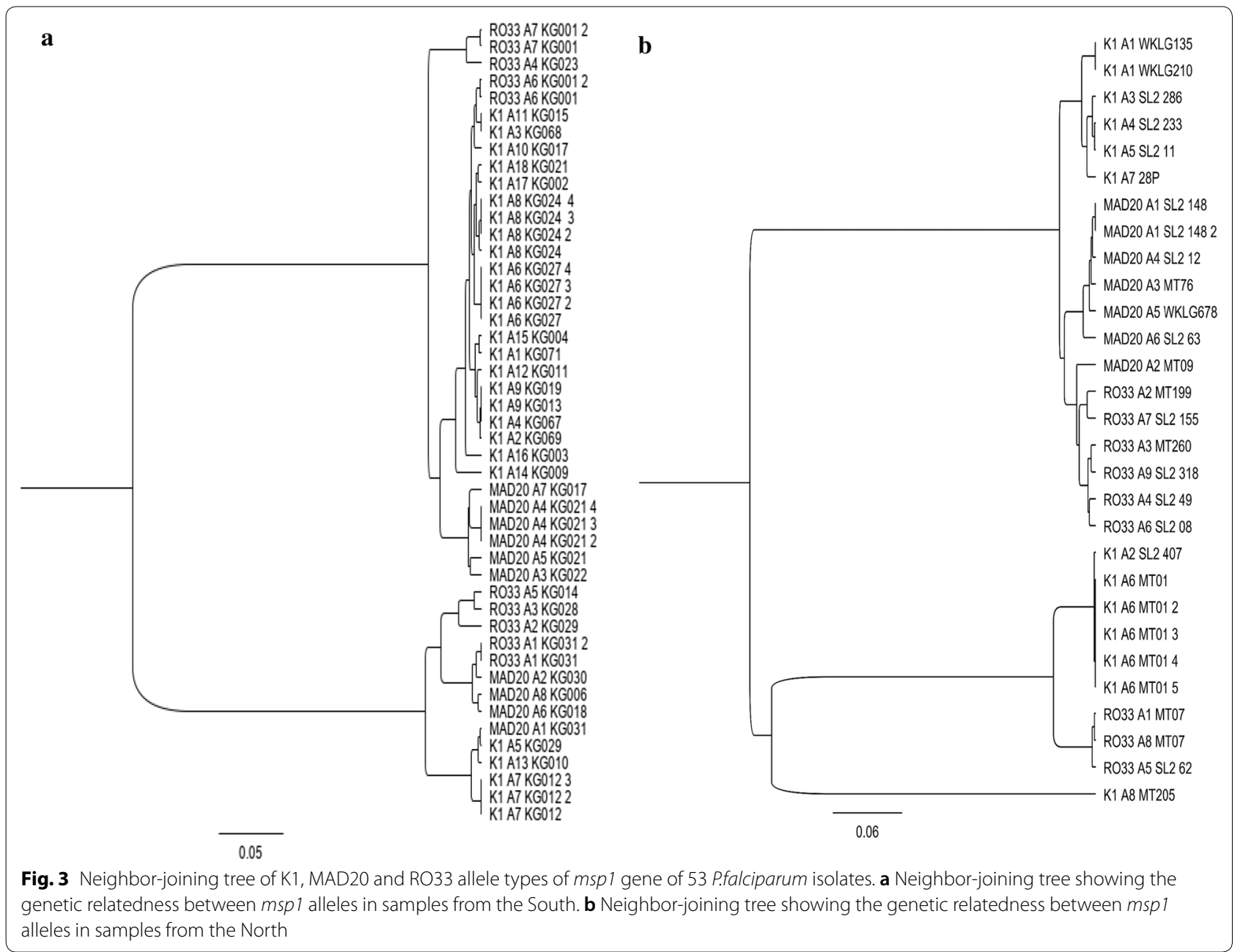

Table 2 Genetic diversity of $m s p 1$ and $m s p 2$ genes of $P$. falciparum isolates from the South (Kedougou) and North (Podor and Matam)

\begin{tabular}{|c|c|c|c|c|}
\hline \multirow[t]{2}{*}{ Genes } & \multicolumn{2}{|l|}{ Msp1 } & \multicolumn{2}{|l|}{ Msp2 } \\
\hline & Kedougou & North area & Kedougou & North area \\
\hline No of Isolate & 28 & 23 & 28 & 25 \\
\hline Clones (N) & 47 & 29 & 76 & 40 \\
\hline Haplotype diversity (Hd) & 0.93 & 0.761 & 0.82 & 0.843 \\
\hline \multicolumn{5}{|l|}{ Nucleotide diversity } \\
\hline$\pi$ & 0.28306 & 0.09457 & 0.48339 & 0.42473 \\
\hline$\theta$ & 0.24245 & 0.16236 & 0.3534 & 0.37802 \\
\hline Tajima's D* test of neutrality & $2.0453^{*}$ & -1.46045 & $5.21073^{*}$ & $3.46684^{*}$ \\
\hline FSTs & $0.19505^{*}$ & & 0.02111 & \\
\hline
\end{tabular}

* indicates the significance at P 0.05 level

\section{Multiplicity of infection (MOI)}

The mean MOI for Pfmsp1, Pfmsp 2 and both genes together in each area are shown in Fig. 5. The mean MOI for Pfmsp 1 was 1.5 in the South and 1.24 in the North, the number of clones per isolate ranged from 1 to 5 in these two regions and no statistically significant difference was 


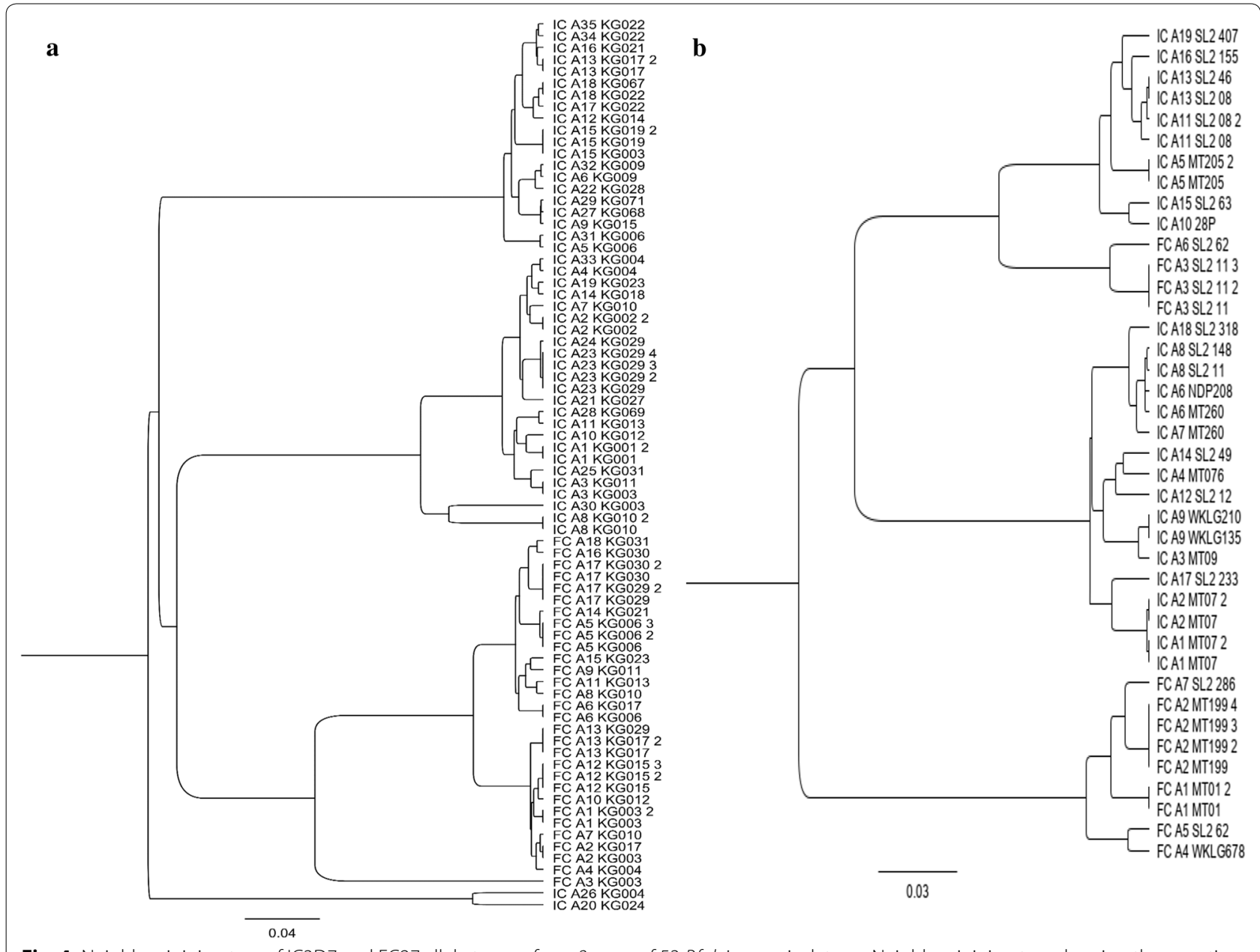

Fig. 4 Neighbor-joining tree of IC3D7 and FC27 allele types of msp2 gene of 53 P.falciparum isolates. a Neighbor-joining tree showing the genetic relatedness between $m s p 2$ alleles in samples from the South. $\mathbf{b}$ Neighbor-joining tree showing the genetic relatedness between $m s p 2$ alleles in samples from the North

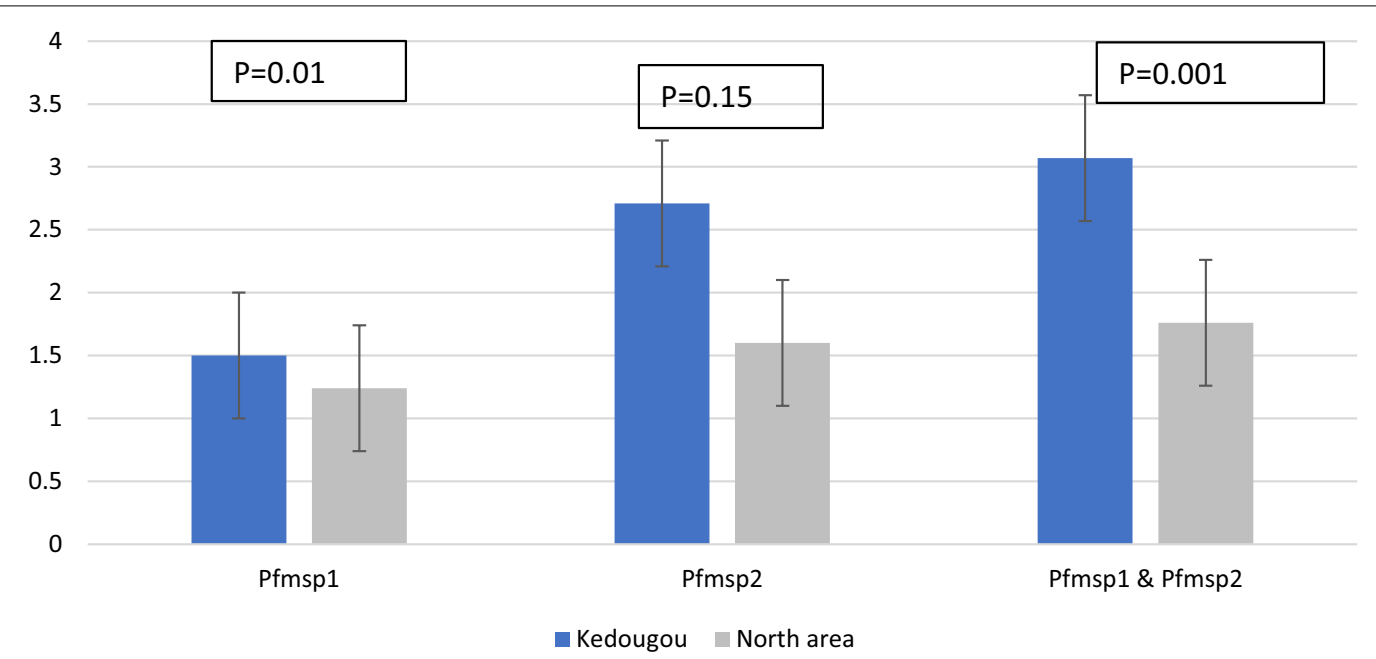

Fig. 5 Plasmodium falciparum multiplicity of infections (MOI) mean for Pfmsp1 and Pfmsp2 genes in the South area and North area. The MOI mean of Pfmsp1 \& Pfmsp2 was statistically different between the South and North $(p=0.001)$ 
observed between regions $(p=0.159)$. For $P f m s p 2$, mean MOI was significantly different between the South and the North $(p=0.010)$. The number of clones per samples ranged from 1 to 7 in the South with a MOI $=2.71$ while in the North a MOI $=1.6$ and the average number of clones varying between 1 and 4. Mean MOI for both genes was 3.07 and 1.76 in the South and North, respectively, with statistically significant differences between areas $(p=0.001)$.

\section{Discussion}

A better understanding of $P$. falciparum population structure could help to improve the local monitoring of parasite transmission, particularly in areas where $P$. falciparum genetic diversity has been poorly documented. Therefore, the aim of this study was to report the genetic diversity of $P$. falciparum and parasite population structure by performing multiplexed amplicon deep sequencing of Pfmsp1 and Pfmsp2 from two understudied areas in Senegal with significantly different endemicity, the Southern (malaria hyper-endemic) and Northern (malaria pre-elimination) areas. A high degree of polymorphism of the genes Pfmsp 1 and Pfmsp 2 was found in Senegal. A total of one hundred thirty-five different alleles were identified; 56 Pfmsp 1 alleles (26 K1-like, 14 MAD20-like and 16 RO33-like) and 79 Pfmsp2 alleles (54 IC3D7-like and 25 FC27-like). These results are consistent with a previous observation of high levels of polymorphism in both Pfmsp1 (8K1-like, 14MAD20-like, 6 RO33-like) and Pfmsp2 (41 IC3D7-like, 18 FC27-like) using an amplicon deep sequencing technique in Myanmar [44]. Similar results have been also reported by Aspeling-Jones et al. who identified 225 different K1-like, 123 different MAD20-like and 9 distinct RO33-like in Africa and Asia [45]. Most of these alleles were detected in the South, hyper-endemic area, 33 and 53 distinct alleles were observed for Pfmsp1 (18 K1-like, 8 MAD20like, and 7 RO33-like) and Pfmsp 2 (35 IC3D7-like and 18 FC27-like), respectively. Comparable results from elsewhere in sub-Saharan Africa (Gabon and Ivory-Cost) reported by Yavo et al. underlined the same diversity with 27 K1-like, 22 MAD20-like and 18 RO33-like alleles for Pfmsp1 and 28 IC3D7-like and 20 FC27-like for Pfmsp 2 [16]. In areas with high malaria transmission intensity the probability of genetic recombination between circulating strains is high and could affected the variation, the numbers and arrangements of amino acid repeats units of Pfmsp1 and Pfmsp2, which are the main factors driving the increased allelic diversity [44, 46-48]. It is known that a large number of mutations in parasite populations arms the organism to successfully battle out adverse environmental conditions through adaptation. Indeed, it has been shown that $P$. falciparum genetic diversity is indicative of the ability of malaria parasites to adapt to their hosts by selection of advantageous traits, such as drug resistance and antigenic variability [49].

For $P f m s p 1$, despite a haplotype diversity of $\mathrm{Hd}=0.76$ in the North, the negative value of TD suggests there is clonal expansion of the parasite. A similar finding was also reported by the team of Daniels et al. in 2013 in Thiès, using a 24 SNP molecular barcode approach [30]. This situation suggests a high self-fertilization rate between genetically identical parasites during the sexual stages in the mosquito in these areas where malaria transmission is declining. However, in the South the $P$. falciparum population exhibits a high $\mathrm{Hd}(\mathrm{Hd}=0.93)$ and a TD value significantly different from expected under the neutral model of molecular evolution $(\mathrm{D}=2.0453)$. This variability in parasite population genetics observed across the two regions reflected the difference in malaria transmission intensity reported in these areas [2]. These findings suggest that the genetic diversity of $P$. falciparum is greater in high malaria transmission areas and decreases when transmission regresses [2, 4]. The neighbour-joining tree of different allele types revealed two parasite clusters in the South as in the North and many clones sharing same patterns in amino acid level showing parental link between strains. Finally, the low Fst value of Pfmsp 1 between parasite population from the South and the North indicates the presence of gene flow between these populations, likely facilitated by extensive human migration events between regions causing the vector's displacement.

For $P f m s p 2$, three clusters with a high $\mathrm{Hd}$ and $\pi$ were observed associated with a balancing selection (Positive TD value) in each area and an almost panmictic parasite population (low Fst and genetic relatedness) between the two studies sites. As widely known, malaria parasites use genetic diversity as an escape measure either from human immunity or treatment by anti-malarials [50, 51]. Therefore the high genetic diversity of parasites found in these areas is alarming. Indeed, a larger number of different allele types in the parasite population may be able help parasites more easily adapt to the environmental conditions such as malaria control measures [52, 53]. In addition, the low genetic differentiation between the parasite populations from the two study sites indicates a gene flow within the population probably deriving from the high mobility of infected human hosts. This situation has been observed to cause malaria outbreaks in malaria residual foci (unpublished data) and a rebound of $P$. falciparum genetic diversity in the low malaria transmission region of Thies, as previously reported [7]. Such events could be a major challenge for malaria control and elimination in Senegal. Multiclonal infections were higher in the South, suggesting that this is more common 
in areas of high malaria endemicity. This is consistent with previous observations for high transmission areas, such as in Ethiopia [24]. Allelic polymorphism was also higher in the South, which could increase the likelihood of recombination (genetic crossing-over) in these areas [46]. Recombination can generate novel parasite variants, giving rise to new genetic diversity that may exhibit phenotypic differences such as virulence, drug resistance or immune evasion $[54,55]$. MOI is an indicator of malaria transmission level because: it has been found to be higher in high malaria transmission areas and decreases when transmission declines [2,56-61]. MOI mean was significantly higher in the South than in the North $(p=0.001)$, suggesting that malaria transmission remains still active in this area. Moreover, the low mean MOI found in the North (1.76), may suggest a decline in malaria transmission levels, underlining the effectiveness of the scale-up in malaria control measures since 2006 [32].

This study was carried out from malaria symptomatic patients. As known, in endemic areas asymptomatic malaria or sub-microscopic infections is thought to represent the majority of the infections [62]. Therefore, missing data about parasites genetic diversity from these asymptomatic patients may constitute a limitation of this study. Despite this limitation, the results of this study contribute insight into the genetic diversity of the P. falciparum population in two malaria endemic areas in Senegal. In addition, this study argues that multiplexed amplicon deep sequencing represents an important advance for surveillance of parasites populations within the country. Although this approach is currently more expensive and longer per-sample that standard genotyping methods it offers several advantages, especially in the ability to scale to large numbers of samples as will be needed for large-scale disease surveillance. The costs of sequencing are also rapidly declining and methods are becoming faster and more portable. Finally, this method allows the sequencing of several genes of interest in one run and can be readily adapted to other genes as the sequencing of anti-malaria resistance markers.

\section{Conclusion}

This study revealed a high genetic diversity of $P f m s p 1$ and $P f m s p 2$ genes in Senegal. Findings also showed an almost panmictic $P$. falciparum population with an important gene flow and MOI disparities between a malaria hotspot (Kedougou, Southern area) and a malaria pre-elimination area (Podor and Matam, Northern areas), a situation that may hamper malaria elimination in these Northern regions. Therefore, continuous molecular epidemiological surveillance to monitor the genetic diversity and parasite population structure in Senegal would be necessary for malaria control in Senegal. Additionally, this study showed that multiplexed amplicon deep sequencing is a useful technique to investigate genetic diversity and molecular epidemiology of $P$. falciparum parasite infections.

\section{Supplementary information}

Supplementary information accompanies this paper at https://doi. org/10.1186/s12936-020-03471-7.

Additional file 1. Multiplexed amplicon deep sequencing data of Pfmspl gene.

Additional file 2. Multiplexed amplicon deep sequencing data of Pfmsp2 gene.

\section{Abbreviations}

NGS: Next generation sequencing; MOI: Multiplicity of infection; PfMSP1: Merozoite surface protein 1 of Plasmodium falciparum; PfMSP2: Merozoite surface protein 2 of Plasmodium falciparum; pfmsp 1: Plasmodium falciparum msp1 Gene; pfmsp2: Plasmodium falciparum msp2 Gene; Hd: Haplotype diversity; $\pi$ : Nucleotide diversity; TD: Tajima's D; PCR: Polymerase chain reaction; HRM: High resolution melting; SNP: Single nucleotide polymorphism; NMCP: National Malaria Control Programme; WHO: World Health Organization; EIR: Entomological inoculation rate; DNA: Deoxyribonucleic acid; RDTs: Rapid Diagnostic Tests; PET: Photo-induced electron transfer; CT: Cycle threshold; HF: High-fidelity; DNTPs: Deoxyribonucleotide triphosphate; UV: Ultraviolet; Fst: F-Statistic; NCBI: National Center for Biotechnology Information; PM: Podor and Matam; KG: Kédougou.

\section{Acknowledgements}

We acknowledge all participants of the study in Senegal. We thank the staffs from Broad Institute of MIT and Harvard, Cambridge, MA, USA for assisting with Illumina sequencing and data analysis pipelines. We thank also Mamane Nassirou Garba, Younouss Diedhiou, Lamine Ndiaye, Amadou Mactar Mbaye and staff of Cheikh Anta Diop University for their contribution in this study.

\section{Authors' contributions}

TN, MS, AG, KS and DP conceived and designed the study. TN, MS and AG carried out the experiments and collected data. TN, MS, AG and KS analysed the data. TN, MS, AG, KS, DP, AKB, ASB, ABD, MAD and KD contributed to writing the manuscript. All authors read and approved the final manuscript.

\section{Funding}

The work was supported by the International Centers of Excellence for Malaria Research, (ICEMR) West Africa (U19AI089696).

\section{Availability of data and materials}

The data supporting the findings of this article are included within the article.

\section{Ethics approval and consent to participate}

The study was approved by the National Ethics Committee for Health Research of Senegal. Before patients were enrolled in the studies sites, benefits and any perceived risks were explained to all participants in French or local languages. Informed consent for adults or guardians consent for children less than 18 years old were obtained before participant recruitment and sample collection.

\section{Consent for publication}

The participants in this study are consent for publication.

\section{Competing interests}

The authors declare that they have no competing interests.

\section{Author details}

${ }^{1}$ Laboratoire de Parasitologie-Mycologie, Université Cheikh Anta Diop de Dakar (UCAD), Hôpital Aristide Le Dantec, Dakar, Senegal. ${ }^{2}$ Broad Institute of MIT and Harvard, Cambridge, MA, USA. ${ }^{3}$ Yale School of Public Health, 60 
College Street, New Haven, CT 06510, USA. ${ }^{4}$ Department of Immunology and Infectious Diseases, Harvard University, Cambridge, MA, USA.

\section{Received: 9 July 2020 Accepted: 30 October 2020}

Published online: 10 November 2020

\section{References}

1. WHO. World malaria report 2018. Geneva, World Health Organization. https://www.who.int/malaria/publications/world-malaria-report-2018/ report/en/.

2. Anderson TJ, Haubold B, Williams JT, Estrada-Franco JG, Richardson L, Mollinedo R, et al. Microsatellite markers reveal a spectrum of population structures in the malaria parasite Plasmodium falciparum. Mol Biol Evol. 2000;17:1467-82.

3. Khaireh BA, Assefa A, Guessod HH, Basco LK, Khaireh MA, Pascual A, et al. Population genetics analysis during the elimination process of Plasmodium falciparum in Djibouti. Malar J. 2013;12:201.

4. Nabet C, Doumbo S, Jeddi F, Konaté S, Manciulli T, Fofana B, et al. Genetic diversity of Plasmodium falciparum in human malaria cases in Mali. Malar J. 2016;15:353.

5. Mohd Abd Razak MR, Sastu UR, Norahmad NA, Abdul-Karim A, Muhammad A, Muniandy PK, et al. Genetic diversity of Plasmodium falciparum populations in malaria declining areas of Sabah, East Malaysia. PLoS One. 2016;11:e0152415.

6. Arnott A, Barry AE, Reeder JC. Understanding the population genetics of Plasmodium vivax is essential for malaria control and elimination. Malar J. 2012;11:14.

7. Daniels RF, Schaffner SF, Wenger EA, Proctor JL, Chang H-H, Wong W, et al. Modeling malaria genomics reveals transmission decline and rebound in Senegal. Proc Natl Acad Sci USA. 2015;112:7067-72.

8. Niang M, Thiam LG, Loucoubar C, Sow A, Sadio BD, Diallo M, et al. Spatiotemporal analysis of the genetic diversity and complexity of Plasmodium falciparum infections in Kédougou Southeastern. Senegal Parasit Vectors. 2017;10:33.

9. Gilson PR, Nebl T, Vukcevic D, Moritz RL, Sargeant T, Speed TP, et al. Identification and stoichiometry of glycosylphosphatidylinositol-anchored membrane proteins of the human malaria parasite Plasmodium falciparum. Mol Cell Proteomics. 2006:5:1286-99.

10. Lin CS, Uboldi AD, Epp C, Bujard H, Tsuboi T, Czabotar PE, et al. Multiple Plasmodium falciparum Merozoite Surface Protein 1 complexes mediate merozoite binding to human erythrocytes. J Biol Chem. 2016;291:7703-15.

11. Baldwin MR, Li X, Hanada T, Liu S-C, Chishti AH. Merozoite surface protein 1 recognition of host glycophorin A mediates malaria parasite invasion of red blood cells. Blood. 2015;125:2704-11.

12. Tanabe K, Mackay M, Goman M, Scaife JG. Allelic dimorphism in a surface antigen gene of the malaria parasite Plasmodium falciparum. J Mol Biol. 1987;195:273-87.

13. Mwingira F, Nkwengulila G, Schoepflin S, Sumari D, Beck H-P, Snounou $\mathrm{G}$, et al. allele frequency and diversity in sub-Saharan Africa. Malar J. 2011;10:79.

14. Ahmedou Salem MSO, Ndiaye M, OuldAbdallahi M, Lekweiry KM, Bogreau $H$, Konaté $L$, et al. Polymorphism of the merozoite surface protein-1 block 2 region in Plasmodium falciparum isolates from Mauritania. Malar J. 2014:13:26.

15. Soulama I, Nébié I, Ouédraogo A, Gansane A, Diarra A, Tiono AB, et al. Plasmodium falciparum genotypes diversity in symptomatic malaria of children living in an urban and a rural setting in Burkina Faso. Malar J. 2009;8:135.

16. Yavo W, Konaté A, Mawili-Mboumba DP, Kassi FK, Tshibola Mbuyi ML, Angora EK, et al. Genetic polymorphism of msp1 and msp2 in Plasmodium falciparum isolates from Côte d'Ivoire versus Gabon. J Parasitol Res. 2016;2016:3074803

17. Khaminsou N, Kritpetcharat O, Daduang J, Charerntanyarak L, Kritpetcharat P. Genetic analysis of the merozoite surface protein-1 block 2 allelic types in Plasmodium falciparum clinical isolates from Lao PDR. Malar J. 2011;10:371.

18. Bouyou-Akotet MK, M'Bondoukwé NP, Mawili-Mboumba DP. Genetic polymorphism of merozoite surface protein-1 in Plasmodium falciparum isolates from patients with mild to severe malaria in Libreville. Gabon Parasite. 2015;22:12.

19. Messerli C, Hofmann NE, Beck H-P, Felger I. Critical evaluation of molecular monitoring in malaria drug efficacy trials and pitfalls of length-polymorphic markers. Antimicrob Agents Chemother. 2017;61:01500-16.

20. Greenhouse B, Myrick A, Dokomajilar C, Woo JM, Carlson EJ, Rosenthal PJ, et al. Validation of microsatellite markers for use in genotyping polyclonal Plasmodium falciparum infections. Am J Trop Med Hyg. 2006;75:836-42.

21. Hosseinzadeh-Colagar A, Haghighatnia MJ, Amiri Z, Mohadjerani M, Tafrihi M. Microsatellite (SSR) amplification by PCR usually led to polymorphic bands: evidence which shows replication slippage occurs in extend or nascent DNA strands. Mol Biol Res Commun. 2016;5:167-74.

22. Van Hong N, Delgado-Ratto C, Thanh PV, Van den Eede P, Guetens P, Binh $\mathrm{NTH}$, et al. Population genetics of Plasmodium vivax in four rural communities in Central Vietnam. PLoS Negl Trop Dis. 2016;10:e0004434.

23. Papa Mze N, Ndiaye YD, Diedhiou CK, Rahamatou S, Dieye B, Daniels RF, et al. RDTs as a source of DNA to study Plasmodium falciparum drug resistance in isolates from Senegal and the Comoros Islands. Malar J. 2015;14:373.

24. Zhong D, Lo E, Wang X, Yewhalaw D, Zhou G, Atieli HE, et al. Multiplicity and molecular epidemiology of Plasmodium vivax and Plasmodium falciparum infections in East Africa. Malar J. 2018;17:185.

25. Juliano JJ, Porter K, Mwapasa V, Sem R, Rogers WO, Ariey F, et al. Exposing malaria in-host diversity and estimating population diversity by capturerecapture using massively parallel pyrosequencing. Proc Natl Acad Sci USA. 2010;107:20138-43.

26. Koepfli C, Mueller I. Malaria epidemiology at the clone level. Trends Parasitol. 2017;33:974-85.

27. Lerch A, Koepfli C, Hofmann NE, Messerli C, Wilcox S, Kattenberg JH, et al. Development of amplicon deep sequencing markers and data analysis pipeline for genotyping multi-clonal malaria infections. BMC Genomics. 2017; 18:64.

28. Leclerc MC, Durand P, de Meeûs T, Robert V, Renaud F. Genetic diversity and population structure of Plasmodium falciparum isolates from Dakar, Senegal, investigated from microsatellite and antigen determinant loci. Microb Infect. 2002:4:685-92.

29. Ahouidi AD, Bei AK, Neafsey DE, Sarr O, Volkman S, Milner D, et al. Population genetic analysis of large sequence polymorphisms in Plasmodium falciparum blood-stage antigens. Infect Genet Evol. 2010;10:200-6.

30. Daniels R, Chang H-H, Séne PD, Park DC, Neafsey DE, Schaffner SF, et al. Genetic surveillance detects both clonal and epidemic transmission of malaria following enhanced intervention in Senegal. PLoS ONE. 2013;8:e60780.

31. WHO. Communicable diseases cluster: severe falciparum malaria. Trans $R$ Soc Trop Med Hyg. 2000;94:0S1-S9.

32. Plan stratégique national de lutte contre le paludisme au Sénégal 2016-2020. https://www.pnlp.sn/wp-content/uploads/2016/08/PNLP_ PSN_VFF_03-02-2016.pdf.

33. Lucchi NW, Karell MA, Journel I, Rogier E, Goldman I, Ljolje D, et al. PETPCR method for the molecular detection of malaria parasites in a national malaria surveillance study in Haiti, 2011. Malar J. 2014;13:462.

34. Lima GFM de C, Lucchi NW, Silva-Flannery L, Macedo-de-Oliveira A, Hristov AD, Inoue J, et al. Still searching for a suitable molecular test to detect hidden Plasmodium infection: a proposal for blood donor screening in Brazil. PLoS One. 2016;11:e0150391.

35. Snounou G, Zhu X, Siripoon N, Jarra W, Thaithong S, Brown KN, et al. Biased distribution of msp1 and msp2 allelic variants in Plasmodium falciparum populations in Thailand. Trans R Soc Trop Med Hyg. 1999;93:369-74.

36. Matranga CB, Andersen KG, Winnicki S, Busby M, Gladden AD, Tewhey $R$, et al. Enhanced methods for unbiased deep sequencing of Lassa and Ebola RNA viruses from clinical and biological samples. Genome Biol. 2014;15:519.

37. Park D, Tomkins-Tinch C, Ye S, et al. broadinstitute/viral-ngs: v1.19.2. Geneva: Zenodo, February 6, 2018 (https://zenodo.org/record/1167849).

38. Grabherr MG, Haas BJ, Yassour M, Levin JZ, Thompson DA, Amit I, et al. Full-length transcriptome assembly from RNA-Seq data without a reference genome. Nat Biotechnol. 2011;29:644-52.

39. Hall TA. BioEdit: a user-friendly biological sequence alignment editor and analysis program for Windows 95/98/NT. Nucl Acids Symp Ser. 1999:41:95-8. 
40. Librado P, Rozas J. DnaSP v5: a software for comprehensive analysis of DNA polymorphism data. Bioinformatics. 2009;25:1451-2.

41. Tajima F. Statistical method for testing the neutral mutation hypothesis by DNA polymorphism. Genetics. 1989;123:585-95.

42. Weir BS, Cockerham CC. Estimating f-statistics for the analysis of population structure. Evolution. 1984;38:1358-70.

43. Agyeman-Budu A, Brown C, Adjei G, Adams M, Dosoo D, Dery D, et al. Trends in multiplicity of Plasmodium falciparum infections among asymptomatic residents in the middle belt of Ghana. Malar J. 2013;12:22.

44. Lê HG, Kang JM, Jun H, Lee J, Thái TL, Myint MK, et al. Changing pattern of the genetic diversities of Plasmodium falciparum merozoite surface protein-1 and merozoite surface protein-2 in Myanmar isolates. Malar J. 2019:18:241.

45. Aspeling-Jones H, Conway DJ. An expanded global inventory of allelic variation in the most extremely polymorphic region of Plasmodium falciparum merozoite surface protein 1 provided by short read sequence data. Malar J. 2018;17:345.

46. Ferreira M. Sequence diversity and evolution of the malaria vaccine candidate merozoite surface protein-1 (MSP-1) of Plasmodium falciparum. Gene. 2003;304:65-75.

47. Kang JM, Moon SU, Kim JY, Cho SH, Lin K, Sohn WM, et al. Genetic polymorphism of merozoite surface protein-1 and merozoite surface protein-2 in Plasmodium falciparum field isolates from Myanmar. Malar J. 2010;9:131.

48. Conway DJ, Roper C, Oduola AM, Arnot DE, Kremsner PG, Grobusch MP, et al. High recombination rate in natural populations of Plasmodium falciparum. Proc Natl Acad Sci USA. 1999;96:4506-11.

49. Ghansah A, Amenga-Etego L, Amambua-Ngwa A, Andagalu B, Apinjoh T, Bouyou-Akotet $M$, et al. Monitoring parasite diversity for malaria elimination in sub-Saharan Africa. Science. 2014;345:1297-8.

50. Osier FHA, Weedall GD, Verra F, Murungi L, Tetteh KKA, Bull P, et al. Allelic diversity and naturally acquired allele-specific antibody responses to Plasmodium falciparum apical membrane antigen 1 in Kenya. Infect Immun. 2010;78:4625-33.

51. Oyebola KM, Idowu ET, Olukosi YA, Awolola TS, Amambua-Ngwa A. Pooled-DNA sequencing identifies genomic regions of selection in Nigerian isolates of Plasmodium falciparum. Parasit Vectors. 2017;10:320.

52. Molina-Cruz A, Barillas-Mury C. The remarkable journey of adaptation of the Plasmodium falciparum malaria parasite to New World anopheline mosquitoes. Mem Inst Oswaldo Cruz. 2014;109:662-7.
53. Rono MK, Nyonda MA, Simam JJ, Ngoi JM, Mok S, Kortok MM, et al. Adaptation of Plasmodium falciparum to its transmission environment. Nat Ecol Evol. 2018;2:377-87.

54. Chenet SM, Schneider KA, Villegas L, Escalante AA. Local population structure of Plasmodium: impact on malaria control and elimination. Malar J. 2012;11:412.

55. Contamin H, Fandeur T, Rogier C, Bonnefoy S, Konate L, Trape JF, et al. Different genetic characteristics of Plasmodium falciparum isolates collected during successive clinical Malaria episodes in Senegalese children. Am J Trop Med Hyg. 1996;54:632-43.

56. Hastings IM, D'Alessandro U. Modelling a predictable disaster: the rise and spread of drug-resistant malaria. Parasitol Today. 2000;16:340-7.

57. Atroosh WM, Al-Mekhlafi HM, Mahdy MA, Saif-Ali R, Al-Mekhlafi AM, Surin J. Genetic diversity of Plasmodium falciparum isolates from Pahang, Malaysia based on MSP-1 and MSP-2 genes. Parasit Vectors. 2011;4:233.

58. Wanji S, Kengne-Ouafo AJ, Eyong EEJ, Kimbi HK, Tendongfor N, Ndamukong-Nyanga JL, et al. Genetic diversity of Plasmodium falciparum merozoite surface protein-1 block 2 in sites of contrasting altitudes and malaria endemicities in the Mount Cameroon region. Am J Trop Med Hyg. 2012;86:64-774.

59. Nkhoma SC, Nair S, Al-Saai S, Ashley E, McGready R, Phyo AP, et al. Population genetic correlates of declining transmission in a human pathogen. Mol Ecol. 2013;22:273-85.

60. Pumpaibool T, Arnathau C, Durand P, Kanchanakhan N, Siripoon N, Suegorn A, et al. Genetic diversity and population structure of Plasmodium falciparum in Thailand, a low transmission country. Malar J. 2009;8:155.

61. Noviyanti R, Coutrier F, Utami RAS, Trimarsanto H, Tirta YK, Trianty L, et al. Contrasting transmission dynamics of co-endemic Plasmodium vivax and P. falciparum: implications for malaria control and elimination. PLoS Negl Trop Dis. 2015;9:e0003739.

62. Lindblade KA, Steinhardt L, Samuels A, Slutsker L, Kachur P. The silent threat: asymptomatic parasitemia and malaria transmission. Expert Rev Anti Infect Ther. 2013;11:623-63.

\section{Publisher's Note}

Springer Nature remains neutral with regard to jurisdictional claims in published maps and institutional affiliations.
Ready to submit your research? Choose BMC and benefit from:

- fast, convenient online submission

- thorough peer review by experienced researchers in your field

- rapid publication on acceptance

- support for research data, including large and complex data types

- gold Open Access which fosters wider collaboration and increased citations

- maximum visibility for your research: over 100M website views per year

At BMC, research is always in progress.

Learn more biomedcentral.com/submissions 